\title{
Changes in echocardiographic left ventricular minor axis dimensions during exercise in patients with aortic stenosis
}

\author{
MARK DANCY, GRAHAM LEECH, AUBREY LEATHAM
}

From the Cardiac Department, St George's Hospital, London

SUMmaRY Twelve patients with aortic stenosis (gradient $62(25) \mathrm{mm} \mathrm{Hg}$ ), and six normal subjects were examined using $M$ mode echocardiography before and during submaximal bicycle exercise. Normal subjects showed a progressive fall in the end systolic minor axis dimension of the left ventricle and a rise in end diastolic dimension, giving an increase in stroke dimension and shortening fraction of $45 \%$ and $37 \%$ respectively at peak exercise. Patients with aortic stenosis showed no consistent alteration in either end systolic or end diastolic dimension, and consequently stroke dimension was unchanged during exercise. None of the patients with an abnormal exercise response had evidence of left ventricular failure at rest, and all but one completed the exercise protocol without undue dyspnoea.

Non-invasive exercise testing in patients with aortic stenosis may detect abnormalities of left heart function which are not apparent at rest. These abnormalities may provide early evidence either of severe aortic stenosis or of incipient left ventricular failure.

The optimum time for replacement of the stenotic aortic valve is as yet unknown. Clearly, it should precede symptoms from left ventricular failure, but on the other hand premature valve replacement is not yet justified since the long term fate of the replacement valve is unpredictable. A decision based on noninvasive investigations would be ideal. ${ }^{2}$ As exercise testing may reveal abnormalities of left heart function not apparent at rest we used $M$ mode echocardiography to monitor the changes in left ventricular dimensions produced by exercise in normal subjects and patients with aortic stenosis.

\section{Patients and methods}

From among the patients admitted routinely with a diagnosis of aortic stenosis, 16 were selected according to the following criteria: (a) high quality $M$ mode echocardiograms $(b)$ age between 15 and 65 years, $(c)$ no history of recent syncope or severe angina, $(d)$ no restriction of exercise in the months before the study,

Requests for reprints to Dr Mark Dancy, Cardiac Department, St George's Hospital, Blackshaw Road, London SW17 0QT.

Accepted for publication 7 June 1984 and $(c)$ no signs of left ventricular failure at rest. Only 12 of the 16 recordings made from patients with aortic stenosis were clear enough for accurate measurement. Table 1 gives the details of these patients. None of the patients aged $>50$ years had coronary artery disease when subsequently investigated. Nine normal subjects with the same age range served as a control group. Only six recordings from the normal subjects were suitable, and these six subjects had a mean age of 36 (10) years.

\section{EXERCISE TEST}

All subjects underwent routine echocardiography in the supine position. Each subject then sat on a bicycle ergometer, a pillow was placed on the handlebars, and he leaned forward with his elbows on the pillow. ${ }^{3}$ The echocardiogram of the left ventricle was recorded again at rest and the echo transducer position marked on the chest. Exercise was then started at a workload of $25 \mathrm{~W}$ and increased by $25 \mathrm{~W}$ every three minutes up to a maximum of $75 \mathrm{~W}$. The left ventricular echocardiogram and blood pressure were recorded in the last minute at each exercise level. Subjects were asked to report any symptoms immediately they noticed them, regardless of their apparent import- 
Table 1 Details of patients with aortic stenosis

\begin{tabular}{llcl}
\hline $\begin{array}{l}\text { Case } \\
\text { No }\end{array}$ & $\begin{array}{c}\text { Age } \\
(y r)\end{array}$ & $\begin{array}{l}\text { Pressure } \\
\text { gradient } \\
(\mathbf{m m} \mathbf{H g})\end{array}$ & Coronary arteries \\
\hline 1 & 17 & 55 & Not investigated \\
2 & 56 & 100 & Normal \\
3 & 16 & 40 & Not investigated \\
4 & 60 & 110 & Normal \\
5 & 47 & 100 & Not investigated \\
6 & 41 & 30 & Not investigated \\
7 & 45 & 80 & Normal, but RCA not cannulated \\
8 & 31 & 65 & Not investigated \\
9 & 15 & 80 & Not investigated \\
10 & 64 & 65 & Normal \\
11 & 16 & 60 & Not investigated \\
12 & 32 & 55 & Not investigated \\
Mean & 37 & 62 & \\
SD & $17 \cdot 4$ & $25 \cdot 4$ & \\
\hline
\end{tabular}

RCA, right coronary artery.

ance, and the test was stopped if there was angina or arrhythmia.

\section{MEASUREMENTS}

The ventricular dimensions were measured in at least six cycles at each stage of exercise using the leading edge method (Fig .1). End systolic dimension (ESD) was taken as the minimum dimension and end diastolic dimension (EDD) as the maximum dimension. Both of these points could be determined accurately using a set square and dividers. The change in left ventricular cavity size associated with contraction was expressed as stroke dimension (EDD-ESD) or shortening fraction ((EDD-ESD)/EDD). The dimensions at each stage of exercise were compared using the paired $t$ test.

The interpretation of the echocardiograms was frequently difficult, and sometimes extrapolation was made from the upright resting trace in order to define left ventricular cavity boundaries in subsequent recordings when respiration made the detail less clear.

\section{Results}

There were no major problems during the submaximal exercise tests. One patient had to stop at the end of stage $2(50 \mathrm{~W})$ because of angina. Table 2 shows the changes in heart rate and blood pressure. There was a tendency for the heart rate of the control subjects to be lower than that of the patients at every stage of
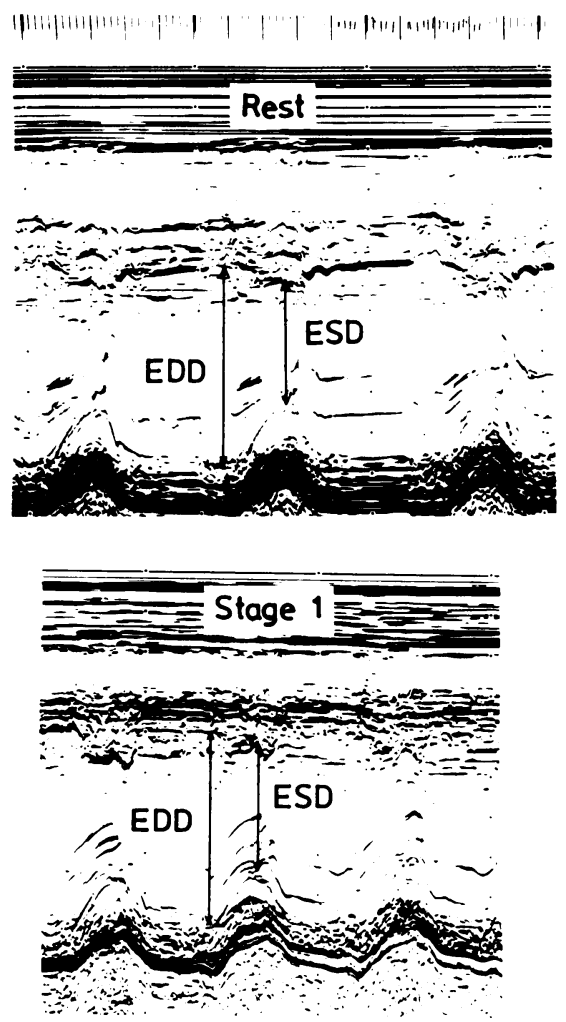
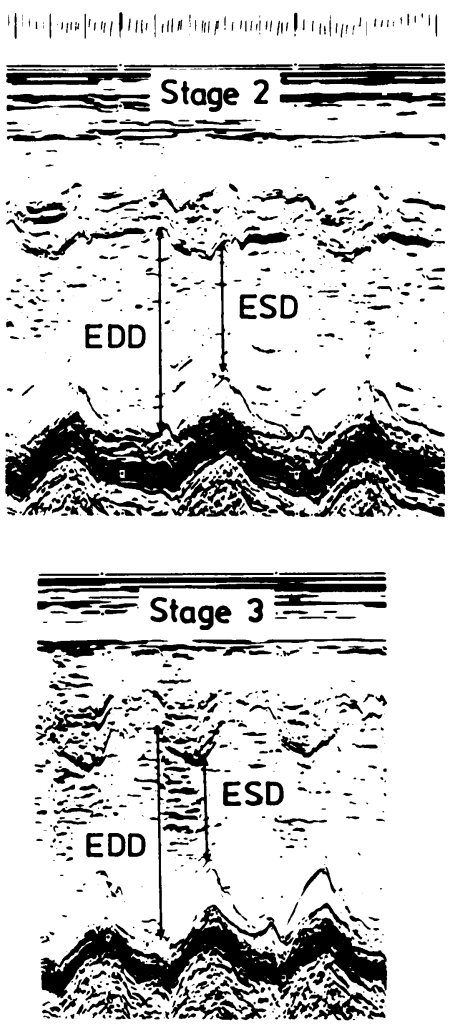

Fig. $1 M$ mode echocardiograms recorded at rest and during exercise in the upright position (stages 1-3). ESD, end systolic dimension; $E D D$, end diastolic dimension. 


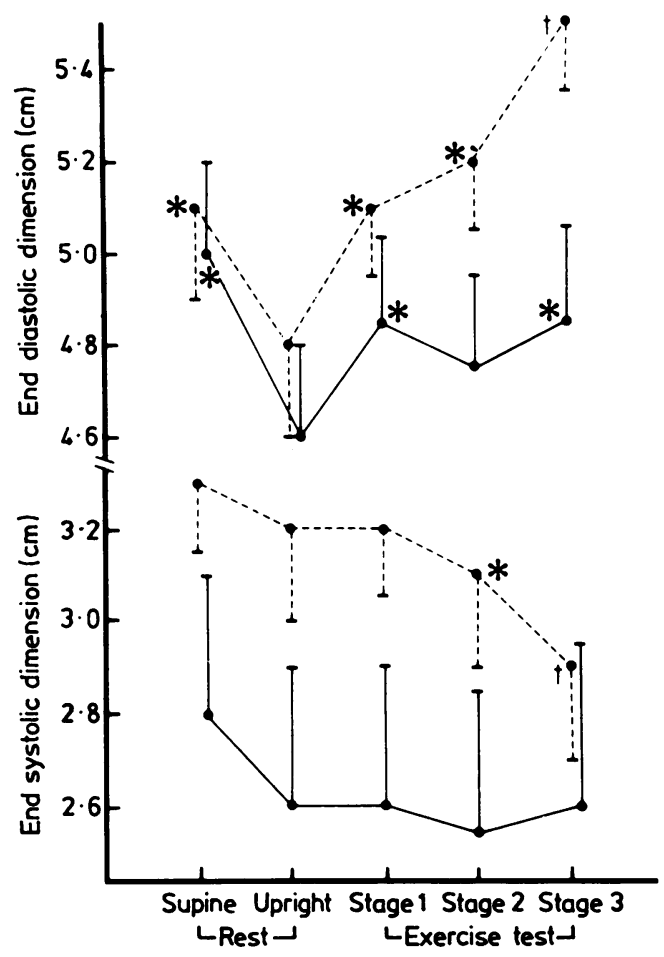

Fig. 2 Changes in end systolic dimension and end diastolic dimension in normal subjects (broken lines) and patients with aortic stenosis (solid lines) when resting supine and upright and at various stages of upright exercise. Values are mean (SD). ${ }^{\star} p<0.01$ compared with resting value; $\dagger_{p}<0.01$ compared with stage 1 value.

exercise, although there were no significant differences between the two groups by the $t$ test. Both systolic and diastolic blood pressure tended to be higher in the control subjects than in the patients, but the means were not significantly different.

\section{DIMENSION CHANGES IN RELATION TO POSTURE AND EXERCISE \\ Normal subjects}

Fig. 2 shows the left ventricular dimension changes.

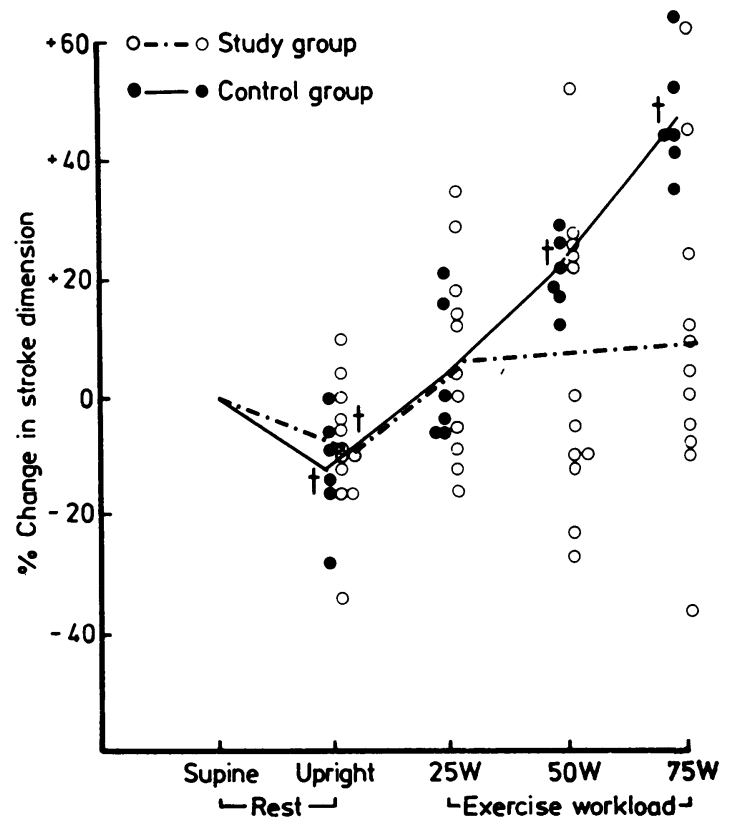

Fig. 3 Percentage change in stroke dimension in normal subjects (closed circles) and patients with aortic stenosis (open circles) during exercise. The lines join the means for each group at each workload. $+p<0.01$ compared with $0 \%$.

When the normal subjects sat upright there were falls in both end systolic and end diastolic dimension, although only the fall in the second was significant. The result of this was a significant fall in stroke dimension (Fig. 3). When exercise started there was a small rise in end diastolic dimension, and end systolic dimension stayed constant. At the end of stages 2 and 3 there were significant rises in end diastolic dimension and falls in end systolic dimension, resulting in a mean increase of $42 \%$ in stroke dimension and of $37 \%$ in shortening fraction $(p<0.01$ for both).

\section{Patients with aortic stenosis}

Patients with aortic stenosis showed almost identical

Table 2 Changes in heart rate and blood pressure in patients with aortic stenosis (study group) and normal subjects (controls)

\begin{tabular}{|c|c|c|c|c|c|c|}
\hline & \multicolumn{2}{|c|}{ Heart rate (beats/min) } & \multicolumn{4}{|c|}{ Blood pressure (mm $\mathrm{Hg}$ ) } \\
\hline & \multirow{2}{*}{$\begin{array}{l}\text { Study } \\
\text { group }\end{array}$} & \multirow[t]{2}{*}{ Controls } & \multicolumn{2}{|c|}{ Study group } & \multicolumn{2}{|l|}{ Controls } \\
\hline & & & Systolic & Diastolic & Systolic & Diastolic \\
\hline $\begin{array}{l}\text { Resting: } \\
\text { Supine } \\
\text { Upright }\end{array}$ & $\begin{array}{l}68(12) \\
81(15)\end{array}$ & $\begin{array}{l}63(12) \\
72(12)\end{array}$ & $119(12)$ & $74(8)$ & $120(3)$ & $80(4)$ \\
\hline $\begin{array}{l}\text { During exercise: } \\
\text { Stage } 1 \\
\text { Stage } 2 \\
\text { Stage } 3\end{array}$ & $\begin{array}{r}97(14) \\
111(18) \\
131(29)\end{array}$ & $\begin{array}{r}84(14) \\
97(18) \\
114(21)\end{array}$ & $\begin{array}{l}123(15) \\
128(13) \\
124(17)\end{array}$ & $\begin{array}{l}79(8) \\
78(10) \\
76(10)\end{array}$ & $\begin{array}{l}135(17) \\
130(12) \\
142(3)\end{array}$ & $\begin{array}{l}89(14) \\
88(15) \\
87(16)\end{array}$ \\
\hline
\end{tabular}


responses to the control group when sitting upright. When exercise started there was an immediate increase in end diastolic dimension which returned to the supine value, but unlike the changes seen in the control subjects there was no further increase in end diastolic dimension at stages 2 and 3. End systolic dimension did not alter appreciably during exercise, and neither stroke dimension nor shortening fraction showed a significant increase.

\section{Discussion}

In the past there has been considerable controversy about the normal response of the heart to exercise. A major part of the increase in cardiac output during exercise is achieved by increasing heart rate. What is less clear is the contribution from the increase in stroke volume. In animals with denervated hearts stroke volume may increase appreciably if heart rate does not rise normally. ${ }^{45}$ Until recently, however, it is not known whether or not this mechanism operated under normal exercise conditions.

There are two ways in which stroke volume might increase on exercise. Firstly, some mechanism-for example circulating catecholamines-might potentiate the contraction of the myocardium thereby increasing emptying (smaller end systolic volume from the same end diastolic volume). Secondly, the end diastolic volume might increase, perhaps because of increased venous return, bringing the FrankStarling mechanism into play by increasing fibre length (same end systolic volume but larger end diastolic volume).

Several invasive and non-invasive methods have been used to investigate the effect of exercise on the heart. Early invasive studies of stroke volume changes gave conflicting results, although differences between these studies could to a certain extent be explained by postural changes, ${ }^{6}$ as some subjects were exercised supine and some upright. Two important studies compared resting and exercise measurements with the subjects upright, and these showed increases in stroke volume ranging from $25 \%$ to $100 \%$ in normal subjects. ${ }^{78}$

The newer techniques of gated blood pool scanning $^{910}$ and $M$ mode echocardiography ${ }^{11-13}$ have allowed changes in stroke volume to be examined more directly. Stroke volume increases during exercise in both the supine and upright positions, but supine cavity dimensions are larger than upright cavity dimensions at each workload. Although end systolic volume (or dimension) clearly decreases during exercise, changes in end diastolic volume (or dimension) have been smaller and less easily detected.

Similar studies have been carried out in patients with aortic stenosis. Gorlin et al investigated four patients with aortic stenosis and found that stroke volume failed to rise during exercise, although cardiac output rose owing to a rise in heart rate. ${ }^{14}$ They pointed out that with a fixed and severely stenotic aortic valve orifice the increase in left ventricular pressure necessary to raise stroke volume from $65 \mathrm{ml}$ to 80 $\mathrm{ml}$ would be $70 \mathrm{~mm} \mathrm{Hg}$. Comparable results have been reported by others both in adults ${ }^{1516}$ and in children. ${ }^{17-19}$

In the present study the patients with aortic stenosis showed normal responses when changing from the supine to the upright position, ${ }^{20}$ but collectively their response to exercise was highly abnormal. There were a variety of individual responses to exercise among the patients (Fig. 3), and only two had responses similar to the control subjects. One of these (case 3), a young man, had one of the lowest gradients in the group.

The normal fall in end systolic dimension with exercise may be an important part of the mechanism for increasing the rate of ventricular filling during exercise when filling time is reduced. It has ben suggested that the ventricle sucks blood in during the early part of diastole, this property being dependent on elastic recoil.21 If this is so, then a fall in end systolic dimension during exercise would have the advantage on increasing the rate of ventricular filling. Those patients with aortic stenosis whose end systolic dimension did not decrease during exercise would be unable to profit from this mechanism, and left ventricular filling rate would remain at resting levels. Furthermore, in some patients end systolic dimension actually increased during exercise, and they would be expected to have a reduced filling rate at a time when filling needed to be maximal. The consequent reduction in stroke output implied by a fall in stroke dimension would increase with more severe exercise and could conceivably cause syncope. Abnormalities of diastolic function during exercise, which could well explain these effects, have recently been reported by Oldershaw et al in patients after aortic valve replacement. 22

If there is no decrease in end systolic dimension in patients with aortic stenosis stroke volume can increase only if end diastolic dimension increases. With hypertrophied and non-compliant ventricles, however, a change in end diastolic dimension would be accompanied by a large rise in end diastolic pressure (unless by some obscure mechanism compliance could fall with exercise). If stroke dimension remains constant any increase in cardiac output during exercise must be accomplished by an increase in heart rate, and it was of interest that the patients did tend to have higher heart rates than the control subjects in the present study.

The abnormalities seen in these patients may be 
due to outflow obstruction, poor left ventricular function (systolic or diastolic), or a combination of both. We do not pretend that exercise testing can separate the contributions of these elements. Nevertheless, we believe it may be an advantage to assess the whole of the left heart as a functional unit. A left ventricle with "good" function under normal loading conditions may be in great difficulty when faced with a severely stenotic aortic valve, and the earlier it is recognised that the left heart as a whole is unable to function normally the better the potential result from aortic valve replacement. The value of exercise testing resides in its potential to provide early evidence- of functional impairment in asymptomatic patients with aortic stenosis.

Measurement of submaximal exercise responses in aortic stenosis offers a new and potentially sensitive method for the early detection of deteriorating left heart function. Although $M$ mode echocardiography was used in this study, it was difficult to obtain clear recordings in all case, and nuclear ventriculography may prove superior for this purpose.

\section{References}

1 St John Sutton MG, St John Sutton M, Oldershaw P, et al. Valve replacement without preoperative cardiac catheterisation. $N$ Engl f Med 1981; 305: 1233-8.

2 Hall RJC, Kadushi OA, Evemy K. Is cardiac catheterisation necessary in the assessment of patients for valve surgery? In: Hunter S, Hall RJC, eds. Echocardiography 2. Edinburgh: Churchill Livingstone. 1984 (in press).

3 Amon KW, Crawford MH. Upright exercise echocardiography. $F C U$ 1979; 7: 373-376.

4 Donald DE, Shepherd JT. Response to exercise in dogs with cardiac denervation. Am F Physiol 1963; 205: 393400.

5 Bruce TA, Chapman CB, Baker O, Fisher JN. The role of autonomic and myocardial factors in cardiac control. $\mathcal{F}$ Clin Invest 1963; 42: 721-6.

6 Rushmer RF. Constancy of stroke volume in ventricular responses to exertion. Am $\mathcal{F}$ Physiol 1959; 196: 745-50.

7 Theilen EO, Gregg DE, Rotta A. Exercise and cardiac work response at high altitude. Circulation 1955; 12: 383-90.

8 Mitchell JH, Sproule BJ, Chapman CB. The physiological meaning of the maximal oxygen intake test. $\mathcal{f}$ Clin Invest 1958; 37: 538-47.
9 Rerych SK, Scholz PM, Newman GE, Sabiston DC Jr, Jones RH. Cardiac function at rest and during exercise in normals and patients with coronary heart disease: evaluation by radionuclide angiocardiography. Ann Surg 1978; 187: 449-64.

10 Poliner LR, Dehmer GJ, Lewis SE, Parkey RW, Blomqvist CG, Willerson JT. Left ventricular performance in normal subjects: a comparison of the responses to exercise in the upright and supine positions. Circulation 1980; 62: 528-34.

11 Stein RA, Michielli D, Fox EL, Krasnow N. Continuous ventricular dimensions in man during supine exercise and recovery: an echocardiographic study $\mathrm{Am} \mathcal{F}$ Cardiol 1978; 41: 655-60.

12. Crawford MH, White DH, Amon KW. Echocardiographic evaluation of left ventricular size and performance during handgrip and supine and upright bicycle exercise. Circulation 1979; 59: 1188-96.

13 Weiss JL, Weisfeldt ML, Mason SJ, Garrison JB, Livengood SV, Fortuin NJ. Evidence of Frank-Starling effect in man during severe semisupine exercise. Circulation 1979; 59: 655-61.

14 Gorlin R, McMillan IKR, Medd WE, Matthews MB, Daley $R$. Dynamics of the circulation in aortic valvular disease. Am $\mathcal{F}$ Med 1955; 18: 855-70.

15 Lee SJK, Jonsson B, Bevegård S, Karlöf I, Aström H. Hemodynamic changes at rest and during exercise in patients with aortic stenosis of varying severity. Am Heart f 1970; 79: 318-31.

16 Richardson JW, Anderson FL, Tsagaris TJ. Rest and exercise hemodynamic studies in patients with isolated aortic stenosis. Cardiology 1979; 64: 1-11.

17 Hugenholtz PG, Nadas AS. Exercise studies in patients with congenital heart disease. Pediatrics 1963; 32: 769 775.

18 Cueto L, Moller JH. Haemodynamics of exercise in children with isolated aortic valvular disease. Br Heart $\mathcal{F}$ 1973; 35: 93-8.

19 Truccone NJ, Steeg CN, Dell R, Gersony WM. Comparison of the cardiocirculatory effects of exercise and isoproterenol in children with pulmonary or aortic valve stenosis. Circulation 1977; 56: 79-82.

20 Goldstein RE, Bennett ED, Leech GL. Effect of glyceryl trinitrate on echocardiographic left ventricular dimensions during exercise in the upright position. $\mathrm{Br}$ Heart $\mathcal{F}$ 1979; 42: 245-54.

21 Brecher GA, Kolder H, Horres AD. Ventricular volume of nonbeating excised dog hearts in the state of elastic equilibrium. Circ Res 1966; 19: 1080-5.

22 Oldershaw PJ, Dawkins KD, Ward DE, Gibson DG. Diastolic mechanisms of impaired exercise tolerance in aortic valve disease. $\mathrm{Br}$ Heart $\mathcal{f}$ 1983; 49: 568-73. 